\title{
Improvement of Evidence-Based Practice through Education and Training Interventions among Nursing Students
}

\author{
Wafaa Mohamed A. Shokry ${ }^{(1)}$. Manal S. Moustafa Saleh ${ }^{(2)}$ \\ ${ }^{(1)}$ Lecturer of nursing administration, Faculty of nursing, Monoufia University. Egypt \\ ${ }^{(2)}$ Lecturer of nursing administration, Faculty of nursing, Zagazig University. Egypt
}

\begin{abstract}
The new trend toward evidence-based practice improvement and nursing care underscores the need for redesigning care that is effective and efficient. The aim of this research was to evaluate the efficacy of education and training interventions to improve EBP' knowledge, skills, and, attitudes among nursing students in Shaqra University. Design: A quasi-experimental pre-test, post-test, and follow-up design was used between an experimental group, and a comparison group. Setting: The study was conducted in the College of Applied Medical Sciences in Shaqra University, and two selected hospitals, KSA. Sample: A convenience sample of 100 nursing students (Undergraduates, parallel and interns) enrolled in the nursing class. Instruments: A selfconstructed questionnaire was developed based on the Evidence-Based Practice Questionnaire (EBPQ). Results: there was a highly significant difference between experimental group and the comparison group in their EBP' skills and knowledge at $p \leq .001$ after an intervention, while, the two groups different significantly in their attitude toward EBP at $p=.010$. Also, there were highly significant improvements in the information resources dimensions in the post-test at $p \leq 0.001$. The major barriers affecting the application of EBP were an inability to understand research and statistics items. Conclusion: Based on the results of this study, education and training interventions of EBP were effective ways in an improvement of the students' knowledge, skills, and attitudes toward adoption of evidence based guidelines in clinical nursing practice. Recommendation: Planning various strategies to progress of research utilization by nurses in their clinical practice.
\end{abstract}

Keywords: TQM: EBP, education and training interventions, barriers, information resources.

\section{Introduction}

Evidence-based nursing practice (EBP) is an important component in the delivery of high-quality care that optimizes patients' health outcomes. EBP enables nursing care guide to be more effective and efficient, more individualized, and to increase effects of the clinical judgment. ${ }^{(1)}$ Educational intervention has been designed for nursing students to improve EBP attitudes, skills and knowledge. ${ }^{(2 \& 3)}$ So, infusion of the knowledge and skills related to evidence-based practice through educational programs is required to promote quality patient care and improve clinical practice. EBP contributes to the development of critical thinking among nursing students through the combination of best evidence, patient values and preferences and clinical experience. () $^{(2)}$

Attitudes are a general evaluation of behavior and are determined by perceptions of its consequences and by beliefs about it. ${ }^{(5)}$ Science EBP is a new approach in the nursing education system, the researcher intended to assess knowledge and attitude of the undergraduate nursing students to determine the efficacy of EBP education. Understanding of student's attitude can influence the development of an appropriate approach to teaching EBP in nursing faculties. ${ }^{(6)}$

EBP is the nursing practice in which the nurse makes clinical decisions on the basis of the best available current research evidence, the nurse's clinical expertise, and the values and preferences of the patients. (7) Evidence-based practice is the utilization of the best research evidence incorporated with clinical experience and integrating patient's values and circumstances in the clinical practice of professional nursing care. ${ }^{(8)}$ The evidence can be used as a basis for healthcare processes, it exists for best practices in assessing of patient conditions, diagnosing of patient problems, planning patient care, interventions to improve the patient's condition, and, evaluating of patient responses to interventions. In addition, the evidence can be used as the basis for policies and procedures. ${ }^{(9)}$

Best evidence includes empirical evidence from; Systematic reviews and meta-analysis, randomized controlled trials, cohort studies, descriptive as well as the use of evidence from case reports and expert opinion. (10) Basically, the EBP process steps including: (1) Ask: Formulating an answerable clinical question through PICO, (2) Acquire: accessing or searching the best evidence, (3) Appraise: Appraising the evidence for its validity and usefulness (4) Apply: integrating the findings with patient' preferences, values and circumstances and clinical expertise and, (5) Assess: evaluating outcomes of the practice change based on evidence. (11)

Information resources of best evidence depend on the type of question and the type of research study. The evidence is published in different sources including; journals, books, research reports, and websites. Also, 
Improvement of Evidence-Based Practice through Education and Training Interventions among ..

some resources involve accessing to a wide range of information types such as Medline, PubMed, Cumulative Index to Nursing and Allied Health Literature (CINAHL) and Cochrane Database. ${ }^{(\mathbf{1 2})}$ The information resources were classified into 3dimensions including print, electronic, and human information sources. (13) Due to wider promoting of evidence-based practice in today's nursing fields, the barriers to implementing EBP have received more and more attention in recent studies. ${ }^{(14)}$ Numerous barriers to implement EBP were; lack time to search, evaluate, analyze, disseminate, and implement research evidence. Inadequate resources and, lack of organization' support for research utilization are another obstacles mentioned by nurse's students. Also, there are barriers perceived by students such as the absence of student's knowledge about research methods, lack awareness of research findings, and inadequate skills in critical appraisal of evidence and lack of confidence to implement change. ${ }^{(\mathbf{1 5})}$

Several barriers affecting an application of EBP among students were; no enough authority to change nursing intervention for implementing new ideas, lack of resources and inability to understand statistical analysis $(16)$

\section{Justification of the study}

Understanding nursing students' knowledge, skills, and attitudes toward evidence-based practice is a critical step to successfully transforming the student's culture to use best practices in nursing. While EBP has become an integral component of optimal patient care, nursing students practicing in many hospital systems continue to experience barriers to improving evidence-based practice, therefore, it was designed consistent education and training intervention may help students to build positive attitudes, knowledge, and skills are critical to enhance a positive EBP climate in clinical practice.

Aims of the study: $a$ ) to evaluate the efficacy of education and training interventions to improve EBP' knowledge, skills, and, attitudes among nursing students in Shaqra University; $\boldsymbol{b}$ ) Determine information resources of best evidence used by nursing students before and after an intervention; $c$ ) Identify the barriers affecting the application of evidence- based practice among nursing students in Shaqra University.

\section{Research questions were:}

1- What is the difference between experimental group and the comparison group of nursing students in the knowledge, skills, and attitudes toward EBP before, after and three months following the intervention?

2- What is the difference in nursing student's knowledge, skills, and attitudes toward EBP before, after and three months following the intervention?

3- Is there a significant difference in information resources of best evidence used by nursing students before and after intervention?

4- What are the barriers affecting the application of evidence-based practice among nursing students in Shaqra University?

\section{1- Design}

\section{Subjects and Methods}

A quasi-experimental design was used in the study, assigning subjects between an experimental group and a comparison group using pre-test, post-test, and follow-up design. Study participants are equally distributed to experimental group and comparison group.

\section{2- Sample and Setting}

A convenience sample of 100 nursing students who enrolled in the nursing class were; Undergraduate students, Parallel students, and Internship students. The sample participants were assigned into an experimental group $(\mathrm{N}=50)$ and comparison group $(\mathrm{N}=50)$. The current study was conducted in the settings; 1$)$ the college of applied medical sciences in Shaqra University, KSA; 2) Al-Quawayiyah General Hospital and Shaqra General Hospital during SY 2015-2016.

\section{3- Data collection tools.}

A self-constructed questionnaire was developed based on the Evidence-based practice questionnaire (EBPQ), (Majid, et al. 2011) ${ }^{(13)}$ designed to fulfill the aim of this study. The questionnaire sheet consisted of 70 items categorized in; Part I: personal data of the study samples (6 items) including; program, age, grade, experience, marital status and attending EBP training related activities or not. Part II: consisted of 36 items divided into three domains namely; knowledge, skills, and attitudes. Knowledge consisted of (10 items). Skills dimensions consisted of 20 items categorized in 6 subscales namely; A) Applying steps of EBP process (6 items), B) Reading research article (3items), $\boldsymbol{C}$ ) applying research recommendation (2 items), D) Searching options (2 items), E) Boolean operators (3 items) and $\boldsymbol{F}$ ) searching engines (4items). Attitude dimensions consisted of (6 items). Part III: Information sources of best evidence (16 items) categorized in 3 dimensions 
namely; print (5 items), electronic (7items) and, human information sources (4items). Part IV: The barriers affecting the application of EBP among nursing students (12items).

Part II: Five possible responses were present for each item of knowledge and attitudes Likert scale ranged from strongly agree (5), to strongly disagree (1) and skills domain was measured as high, moderate, and low. Part III: Responses were scored as always, sometimes and never. While Part $\boldsymbol{I V}$ responses were ranged from agreeing (3) to disagree (1).

\section{4- Tools validity and reliability}

The content validity of the questionnaire was evaluated by five experts. Modifications were carried out on a clarity of the contents and appropriateness of sentences according to the expert comments. Reliability analysis was conducted to investigate the internal consistency of the instruments used in this study. Reliability alone is not enough to test the internal consistency of the instruments. Therefore, validity was required to validate the questionnaire items of this study. Cronbach alpha coefficients were calculated to measure the reliability of the scales for questionnaire items. ${ }^{(17),(18) \text { and (19) }}$

The following table present the reliability Cronbach alpha and validity coefficients for questionnaire items related to knowledge, skills and attitudes domains, barriers and information resources:

\begin{tabular}{|c|c|c|c|}
\hline Dimensions & N of items & Reliability Cronbach's alpha & Validity coefficients \\
\hline Knowledge & 10 & .945 & .972 \\
\hline Skills & 20 & .961 & .980 \\
\hline Attitudes & 6 & .774 & .879 \\
\hline Barriers & 12 & .900 & .948 \\
\hline Information resources & 16 & .831 & .911 \\
\hline Total & 64 & .906 & .951 \\
\hline
\end{tabular}

The knowledge, skills and, attitudes, barriers and, information resources have strong contents and construct validity and are a reliable measure (ie, internal consistency $\alpha=.906$ with validity $=.95$ ) these have been used extensively in studies exploring EBP in nursing.

\section{5- Pilot Study.}

A pilot study was administered to 10 pilot samples in the applied medical sciences college and two selected hospitals. The purpose of the pilot study was to ascertain the clarity, applicability, and relevance of the questions. It also gave the researchers experience how to estimate the needed time to fill in sheets and how the content are clear for the nursing students. Based on the results of the pilot study needed refinement and modifications of the tools were applied. The subjects included in the pilot study were excluded from the main study sample to ensure the stability of the answer.

\section{6- Ethical consideration.}

Before any attempt to collect data, an official approval was obtained from the dean of the college of applied medical sciences in Shaqra University and medical directors of the two selected hospitals. The purpose of the study was fully explained before obtaining the subjects' consent to participate. Nevertheless, in this study, the principles of anonymity and confidentiality were assured.

\section{7- Procedure.}

A questionnaire was developed by the researchers based on Evidence-based practice questionnaire $(\boldsymbol{E B P Q})$ as a tool to collect data in order to evaluate the efficacy of an education and training interventions to improve EBP' knowledge, skills, and, attitudes among nursing students and determine information resources and barriers through (70) paragraph.

Three periods of data collection: a pre-test and two post-test periods. One post-test period immediately followed the education and training interventions and the second occurred three months after education and training interventions. Data collection was conducted throughout the following 4 stages:

First stage; the EBP questionnaire was distributed to both groups (experimental group and comparison group), each group divided into three categories of nursing students (undergraduate, parallel and, interns). Assessment of EBP' knowledge, skills, and attitudes among nursing students before an intervention. The second stage; based on the findings of the pre-test, an education and training interventions were implemented to study participants. The experimental group of students received two lectures and online training interventions about EBP, while, comparison group received different two lectures and online training about information technology during the same time frame for 3 weeks. 
Improvement of Evidence-Based Practice through Education and Training Interventions among ..

The education and training intervention covered the following topics:

\begin{tabular}{|l|l|}
\hline \multicolumn{1}{|c|}{ Experimental group (EBP) } & Comparison group ( Information technology) \\
\hline Lecture 1: 3hours & Lecture 1:3 hours \\
\hline - Introduction of EBP & - Introduction of information technology \\
- Definition of EBP, best practices, evidence & - Define Nursing Informatics \\
- Steps EBP Process & - Types of information systems used \\
- Create a PICO and a focused clinical question. & - Functions of a nursing information system \\
- Types of Clinical Question. & - Components of a basic database system \\
- Searching best evidence & - Information Security and Confidentiality \\
-Types study design (meta-analysis and & - Information sources. \\
systematic review) & - Importance of network integration for health \\
- Levels of evidence & care delivery \\
\hline Lecture 2: 3hours & Lecture 2: 3hours \\
\hline - Information resources of best evidence & - The Computer-Based Patient Record \\
- Critically appraising the evidence & - Characteristics of the computer-based \\
- Applying evidence & patient record \\
- Audit and feedback & - Legal and ethical issues associated with \\
- Searching Engines & computer-based patient records \\
- Boolean operators. & - Computer technology can be used to \\
- Searching databases & support nursing education \\
- Barriers to implementing EBP & - Barriers of information technology \\
\hline Online Training activity: Intervention on EBP & Online Training activity: Applications of Computers \\
steps through PICO: ( $\mathbf{6}$ hours) & and Information Technology: (6 hours) \\
\hline
\end{tabular}

Third stage: at the end of the education and training intervention immediately, the EBP questionnaire was distributed to both groups on the post-test intervention. Fourth stage: study participants received EBP questionnaire after three months followed an intervention to complete the follow-up form. Data was collected during 2015-2016.

\section{8- Statistical design.}

Frequencies were calculated to describe demographic characteristics of the study sample. Mean differences, and, standard deviations were compared using an Independent sample t-test which was set at $p>0.05$ to determine a significant difference between an experimental group and a comparison group of nursing students in the knowledge, skills, and attitudes toward EBP before, after and three months following the intervention. Friedman test was used to determine a significant difference in nursing student's knowledge, skills, and attitudes toward EBP before, after and three months following the intervention. Also, Paired Independent Sample t-test was used to determine a significant difference in information resources of best evidence used by nursing students before and after the intervention. All analyses were obtained using the statistical package for social sciences (SPSS) version 21

\section{Results}

Table 1. Demographic characteristics of the study sample.

Variables of the study sample were homogeneous in the two groups (experimental and comparison). It's clear from the table1, that little less than half of the nursing students in the experimental group and comparison group (42.0\% and $42.0 \%$ respectively) were undergraduates. Also, the majority of study subjects in the two groups were $58.0 \%$ and $66.0 \%$ respectively aged from 21 to 25 years. The most of two study groups had the same grade were very good. Regard to experience from 1 to 5 years; the most of the students in the experimental and comparison groups were $92.0 \%$ and $70.0 \%$ respectively. Concerning marital status, more than half of the students in the both groups were unmarried. Finally, the most of the nursing students were not attended the EBP training in both groups.

Table 2. Comparison Between Experimental Group and Comparison Group in their EBP' knowledge, Skills and, Attitudes in the Pre-test, Post-test, and Follow-up

The results reported that the nursing students had the lowest mean scores of EBP' knowledge, skills and, attitudes for both groups in pre-test (time $\mathbf{o}_{1}$ ), there was no statistically significant difference between experimental group and comparison group of nursing students before education and training interventions in the EBP' knowledge, skills, and attitudes levels $(t=1.010$ and $P=.315),(t=1.538$ and $P=.128)$ and $(t=1.153$ and $\boldsymbol{P}=.252)$ respectively. Meanwhile, these findings indicated higher mean scores of EBP' knowledge, skills and attitudes in the experimental group than comparison group on post-intervention (time $\mathbf{o}_{2}$ ), there were highly statistically significant difference between experimental group and comparison group after an interventions in the EBP' knowledge and skills dimensions $(\boldsymbol{t}=\mathbf{1 5 . 8 5 9}$ and $\boldsymbol{P}=\mathbf{0 0 0})$, and $(\boldsymbol{t}=\mathbf{1 5 . 7 5}$ and $\boldsymbol{P}=\mathbf{0 0 0})$ respectively, while, the two groups different significantly in their attitude toward EBP at $\boldsymbol{p}=\mathbf{0 . 0 1 0}$. Also, there was a highly significant difference between both groups after three months following an education and training interventions 
Improvement of Evidence-Based Practice through Education and Training Interventions among ..

in the EBP' knowledge and skills dimensions $(t=19.966$ and $P=.000)$ and $(t=16.978$ and $P=.000)$ respectively, While, there was no different significantly between two groups in their attitudes toward EBP at $P=.080$.

Table 3. Effect of Education and training intervention on EBP knowledge, skills and, attitudes in Experimental group $(\mathbf{N}=\mathbf{5 0})$

The results of this study showed that there were highly significant improvements in students' knowledge, skills and, attitudes levels towards evidence-based practice on post-test an intervention with mean rank $(2.23,2.32$ and 2.37) respectively in the experimental group $(n=50)$. Meanwhile, there was higher mean rank in the EBP knowledge and skills than attitude after three months of an education and training interventions.

Table 4. Comparison between mean scores of information resources dimensions in the pre- test, and posttest intervention.

Regarding information resources of best evidence used by nursing students in Shaqra University; there were highly statistically significant improvements in the three information resources dimensions (print, electronic and human) in the post-test in comparison to pre-test at $\mathrm{p} \leq 0.001$.

Table 5. The barriers affecting the application of evidence-based practice among nursing students in Shaqra University.

The majority of nursing students reported that the major barriers affecting application of evidence-based practice were; inability to understand research items (59.0\%), inability to understand statistics terms $(60.0 \%)$, difficulty in judging the quality of research articles ( 55.0\%) and inability to properly interpret the results of research studies $(54.0 \%)$. The next barriers, identified by more than third of students agreed that they have a lack of time for reading research $(37.0 \%)$, inability to apply research results (33\%) and they don't have authority for change $(40 \%)$.

Table1. Demographic characteristics of the study sample.

\begin{tabular}{|c|c|c|}
\hline \multirow[t]{2}{*}{ Characteristics } & Experimental group $(\mathrm{N}=50)$ & Comparison group $(\mathrm{N}=50)$ \\
\hline & $\mathrm{n}(\%)$ & $\mathbf{n}(\%)$ \\
\hline $\begin{array}{cc}\text { Program } & \\
& \text { Undergraduate } \\
& \text { Parallel } \\
\text { Internship }\end{array}$ & $\begin{array}{l}21(42.0) \\
10(20.0) \\
19(38.0) \\
\end{array}$ & $\begin{array}{l}21(42.0) \\
16(32.0) \\
13(26.0)\end{array}$ \\
\hline $\begin{array}{c}15-20 \\
21-25 \\
26-30 \\
30 \text { years > } \\
\end{array}$ & $\begin{array}{r}13(26.0) \\
29(58.0) \\
6(12.0) \\
2(4.0) \\
\end{array}$ & $\begin{array}{l}1(2.0) \\
33(66.0) \\
8(16.0) \\
8(16.0) \\
\end{array}$ \\
\hline $\begin{array}{l}\text { excellent } \\
\text { very good } \\
\text { good } \\
\text { Pass } \\
\end{array}$ & $\begin{array}{c}18(36.0) \\
23(46.0) \\
19(18.0) \\
0(0) \\
\end{array}$ & $\begin{array}{c}17(34.0) \\
24(48.0) \\
8(16.0) \\
1(2.0) \\
\end{array}$ \\
\hline $\begin{array}{cc}\text { Experience } & \\
& 1-5 \text { years } \\
& 6-10 \text { years } \\
& 11-15 \text { years } \\
16 \text { years }> \\
\end{array}$ & $\begin{array}{c}46(92.0) \\
4(8.0) \\
0(0) \\
0(0) \\
\end{array}$ & $\begin{array}{l}35(70.0) \\
9(18.0) \\
3(6.0) \\
3(6.0) \\
\end{array}$ \\
\hline $\begin{array}{c}\text { Marital Status } \\
\text { Married } \\
\text { Unmarried } \\
\text { Divorced } \\
\text { Widow }\end{array}$ & $\begin{array}{c}9(18.0) \\
38(76.0) \\
2(4.0) \\
1(2.0)\end{array}$ & $\begin{array}{c}22(44.0) \\
26(52.0) \\
0(0.0) \\
2(4.0)\end{array}$ \\
\hline $\begin{array}{r}\text { Attending training } \\
\text { No } \\
\text { Yes }\end{array}$ & $\begin{array}{l}40(80.0) \\
10(20.0)\end{array}$ & $\begin{array}{r}39(78.0) \\
11(22.0)\end{array}$ \\
\hline
\end{tabular}


Improvement of Evidence-Based Practice through Education and Training Interventions among ..

Table 2. Comparison Between Experimental Group and Comparison Group for EBP' knowledge, Skills and, Attitudes in the Pre-test, Post-test, and Follow-up

\begin{tabular}{|c|c|c|c|c|}
\hline \multirow{2}{*}{ Dimensions } & \multirow{2}{*}{ 站 } & $\mathbf{O}_{1}$ & $\mathbf{O}_{2}$ & $\mathbf{O}_{3}$ \\
\hline & & Mean \pm SD & Mean \pm SD & Mean \pm SD \\
\hline \multirow[b]{3}{*}{ Knowledge } & EG $(\mathrm{N}=50)$ & $15.16 \pm 4.10$ & $22.57 \pm .1 .72$ & $23.31 \pm 1.37$ \\
\hline & CG $(\mathrm{N}=50)$ & $15.90 \pm \quad 3.23$ & $15.71 \pm \quad 2.528$ & $15.40 \pm 2.43$ \\
\hline & \multicolumn{2}{|c|}{$\begin{array}{l}t=1.010 \\
P=.315\end{array}$} & $\begin{array}{l}\mathrm{t}=15.859 \\
\mathrm{P}=.000\end{array}$ & $\begin{array}{l}\mathrm{t}=19.966 \\
\mathrm{P}=.000^{* *}\end{array}$ \\
\hline \multirow{3}{*}{ Skills } & EG $(\mathrm{N}=50)$ & $31.64 \pm 10.91$ & $52.59 \pm 4.38$ & $54.04 \pm 5.20$ \\
\hline & CG $(\mathrm{N}=50)$ & $34.58 \pm 7.92$ & $36.08 \pm 5.97$ & $36.50 \pm 5.12$ \\
\hline & \multicolumn{2}{|c|}{$\begin{array}{l}\mathrm{t}=1.538 \\
\mathrm{P}=.128\end{array}$} & $\mathrm{t}=\mathbf{1 5 . 7 5} \mathrm{P}=.000 * *$ & $\begin{array}{c}\mathrm{t}=\mathbf{1 6 . 9 7 8} \\
\mathrm{P}=.000 * *\end{array}$ \\
\hline \multirow{3}{*}{ Attitudes } & EG $(\mathrm{N}=50)$ & $9.14 \pm 1.98$ & $10.56 \pm 1.84$ & $9.94 \pm 1.75$ \\
\hline & CG $(\mathrm{N}=50)$ & $9.71 \pm 1.73$ & $9.46 \pm 2.34$ & $10.56 \pm 1.73$ \\
\hline & \multicolumn{2}{|c|}{$\begin{array}{l}\mathrm{t}=1.153 \\
\mathrm{P}=.252\end{array}$} & $\begin{array}{l}t=-2.618 \\
P=.010^{*}\end{array}$ & $\begin{array}{l}t=1.767 \\
P=.080\end{array}$ \\
\hline \multicolumn{5}{|c|}{$\begin{aligned} \text { Note: No statistically significant at } \mathrm{P}>0.05 \quad * \text { Statistically significant at } \mathrm{p} \leq 0.05 \\
* * \text { Highly statistically significant at } \mathrm{p} \leq 0.001\end{aligned}$} \\
\hline
\end{tabular}

Table 3. Effect of Education and Training Interventions on EBP knowledge, skills and, attitudes in Experimental group ( $\mathrm{N}=50)$ According to Friedman Test

\begin{tabular}{|c|c|c|c|c|c|}
\hline \multirow{2}{*}{$\begin{array}{l}\text { Evidence- base practice } \\
\text { Dimensions }\end{array}$} & Pre-test $\left(\mathrm{O}_{1}\right)$ & Post-test $\quad\left(\mathrm{O}_{2}\right)$ & Follow-up $\left(\mathrm{O}_{3}\right)$ & \multirow[t]{2}{*}{ df } & \multirow[t]{2}{*}{ Asymp. Sig } \\
\hline & Mean Rank & Mean Rank & Mean Rank & & \\
\hline Knowledge & 1.06 & 2.23 & 2.71 & 2 & $.000 * *$ \\
\hline Skills & 1.14 & 2.32 & 2.54 & 2 & $.001 * *$ \\
\hline Attitudes & 1.64 & 2.37 & 1.99 & 2 & $.001 * *$ \\
\hline \multicolumn{6}{|c|}{$\begin{array}{l}\text { Note: } \\
* * \text { Highly statistically significant at } \mathrm{p} \leq 0.001\end{array}$} \\
\hline
\end{tabular}

Table 4. Comparison between mean scores of information resources dimensions in the pre- test, and post-test of an intervention according to Paired Sample t-tests

\begin{tabular}{|l|c|c|c|c|c|}
\hline $\begin{array}{c}\text { Information Resources } \\
\text { Dimensions }\end{array}$ & $\mathbf{n}$ & Pre-test & Post-test & \multirow{2}{*}{ t-test } & P-value \\
\cline { 3 - 4 } & & Mean $\pm($ SD. $)$ & Mean $\pm($ SD. $)$ & & $0.001^{* *}$ \\
\hline Print information & 100 & $8.19 \pm 1.63$ & $9.37 \pm 2.30$ & $-4.852-$ & $0.001^{* *}$ \\
\hline Electronic information & 100 & $11.66 \pm 3.009$ & $13.55 \pm 2.77$ & $-5.151-$ & $0.001^{* *}$ \\
\hline Human information & 100 & $6.27 \pm 1.58$ & $7.24 \pm 1.46$ & $-5.875-$ & \\
\hline $\begin{array}{l}\text { Note: **Highly statistically significant at p } \leq 0.001 \\
\mathrm{O}_{\mathbf{1}}=\text { before an intervention. } \mathrm{O}_{2}=\text { Immediately after an intervention }\end{array}$ \\
\hline
\end{tabular}

Table 5. The barriers affecting application of evidence-based practice among nursing students in Shaqra University

\begin{tabular}{|l|c|c|c|c|c|c|}
\hline \multirow{2}{*}{ Barriers } & \multicolumn{5}{c|}{ Nursing Students ( N= 100) } \\
\cline { 2 - 7 } & \multicolumn{2}{|c|}{ Agree } & \multicolumn{2}{c|}{$\begin{array}{c}\text { Neither agree nor } \\
\text { disagree }\end{array}$} & \multicolumn{2}{c|}{ Disagree } \\
\cline { 2 - 7 } & $\mathbf{N}$ & $\mathbf{\%}$ & $\mathbf{N}$ & $\mathbf{\%}$ & $\mathbf{N}$ & $\mathbf{\%}$ \\
\hline 1-Inability to understand research items & 59 & 59.0 & 36 & 36.0 & 5 & 5.0 \\
\hline 2-Inability to understand statistics terms & 60 & 60.0 & 34 & 34.0 & 6 & 11.0 \\
\hline 3- Difficulty in judging the quality of research articles & 55 & 55.0 & 34 & 34.0 & 11 & 11 \\
\hline 4-Inability to interpret research results & 54 & 54.0 & 34 & 34.0 & 12 & 12.0 \\
\hline 5-Inability to apply research results & 33 & 33.0 & 39 & 39.0 & 28 & 28.0 \\
\hline 6-Inability to implement research recommendations & 32 & 32.0 & 36 & 36.0 & 32 & 32.0 \\
\hline 7-Lack time for reading research & 37 & 37.0 & 48 & 48.0 & 15 & 15.0 \\
\hline 8-Lack time for apply research & 31 & 31.0 & 41 & 41.0 & 28 & 28.0 \\
\hline 9-Dont have enough resources & 31 & 31.0 & 52 & 52.0 & 17 & 17.0 \\
\hline 10-Dont have authority for change & 40 & 40.0 & 44 & 44.0 & 16 & 16.0 \\
\hline 11-Department' head don't' help me for change & 31 & 31.0 & 44 & 44.0 & 25 & 25.0 \\
\hline 12-My colleagues don't' help me for change & 20 & 20.0 & 49 & 49.0 & 31 & 31.0 \\
\hline
\end{tabular}


Improvement of Evidence-Based Practice through Education and Training Interventions among ..

\section{Discussion}

Increasing demands on healthcare services provided as well as the requirements of quality health care services based on effective interventions impetus towards the provision of evidence-based practice. While EBP has become a vital competency for the nursing students and is an integral component of optimal patient care. Therefore, an education and training interventions have been designed to improve EBP knowledge, skills and attitudes among students. The intention of the current study is to evaluate the efficacy of education and training interventions to improve EBP' knowledge, skills, and, attitudes among nursing students in Shaqra University. Findings of this study are discussed within the following frame of references; information resources of best evidence used by nursing students and the barriers affecting the application of evidence- based practice.

Regarding EBP' knowledge, skills and attitudes between an experimental group and a comparison group before education and training interventions. Our findings of this study indicated that nursing students had the lowest mean scores of EBP' knowledge, skills and, attitudes dimensions for both groups in pre-test, there were no significant difference between an experimental and a comparison groups in pre-test, indicating that both groups were similar in their EBP' knowledge, skills and attitudes levels due to lack of EBP' training and variables of the study participants were homogeneous in the two groups. The present study findings were consistent with Ramos-Morcillo et al. who revealed no significant change were reported between intervention and comparison groups related to EBP' knowledge, skills, practice and attitudes among study participants before educational approach. ${ }^{(20)}$ Also, Melnyk el al. and Olade, indicated that nursing students have a lack of EBP' knowledge and skills before education. ${ }^{(21}$ and 22)

Concerning the $\mathrm{EBP}^{\prime}$ knowledge, skills, and attitudes between an experimental group and comparison group after the education and training intervention. The findings of this study revealed higher mean scores of EBP' knowledge, skills, and attitudes in the experimental group than a comparison group after an intervention, indicating the education and training interventions were competent in the improvement of EBP' knowledge, skills, and attitudes among nursing students at Shaqra University. Regard to experimental group; mean score of EBP' knowledge, skills and attitudes have been increased after education and training interventions. Conversely, in the comparison group; mean score of EBP knowledge among students were not improved due to the lack of nursing students' feedback, While, EBP' skills and attitudes among students changed slightly. The different interventions about information technology were conducted to the comparison group had the same technique and the same period to facilitate comparison between both groups. Our findings analysis revealed there were highly significant difference between an experimental group and comparison group after an education and training interventions in the knowledge and skills $(t=15.85$ and $P=.000)$, and $(t=15.75$ and $P=.000)$ respectively, with significant difference for attitudes $(\boldsymbol{t}=\mathbf{2 . 6 1}$ and $\boldsymbol{P}=\mathbf{0 1 0})$ between them, these finding indicated greater impact on the experimental group versus the comparison group.

The current study findings were compatible with Laibhen-Parkes and Codone, who revealed that nursing students in the study group begun with little EBP' knowledge and skills before an intervention and they reported improvement of EBP' knowledge and skills after an intervention. ${ }^{(23)}$ Also, Ashktorab el al. indicated that the nurses' knowledge and attitudes toward EBP increased after an education, and there was different significantly between two groups in their attitudes and knowledge toward EBP after an intervention at $(\mathrm{P}<0.05)$. (24) These study results are consistent with other studies which revealed statistically significant improvements in nursing students' knowledge, skills and attitude toward evidence-based practice after application an educational program. ${ }^{(25,26}$ and 27) Inconsistent with Mollon et al., who reported that EBP knowledge and skills were not improved by an online educational intervention due to the lack of learning assessment with no statistically significant changes between two groups after their online intervention. ${ }^{(28)}$ In addition, finding of the current study was agreement with Ramos-Morcillo et al., who revealed a significant difference between both groups in their EBP' knowledge and skills post-intervention at $(\mathrm{p} \leq 0.05)$, while, it was disagreement with the same authors who reported no significant changes between both groups in their attitude toward EBP after an intervention. (20)

Furthermore, the findings of the present study revealed that nursing students' knowledge and skills toward EBP were more improved in the experimental group than a comparison group after 3month postintervention, with a highly significant difference between two groups at $(p \leq 0.001)$. Meanwhile, there was no significant difference between both groups in their attitudes toward EBP $(\boldsymbol{t}=\mathbf{1 . 7 6}$ and $P=\mathbf{0 8 0})$, these findings indicating the education and training intervention had the positive impact on students' knowledge and skills toward EBP. On another side, the students' attitudes toward EBP were not improved in the experimental group after three months followed intervention due to students' lack of time that hindered their positive attitudes toward EBP. In the same line, another study by Kim et al., revealed a significant improvement in the EBP knowledge, skills, and practice among nurses after a 9month followed EBP educational program, while, it did not observe any effect on their attitude after the 9month intervention due to differences in cultural, geographic, and professional settings. ${ }^{(29)}$ Also, Gonz'alez-Torrente et al., reported that high scores of nursing students 
identified that EBP' educational intervention did not effect on their attitudes. ${ }^{(30)}$ This result was inconsistent with Majid, who reported that the majority of the nurses were expressed a positive attitude toward EBP. ${ }^{(31)}$ These variations among various studies may be due to differences in the educational level of students.

Regarding information resources dimensions of best evidence used by nursing students before and after intervention; There were highly statistically significant improvements in the three Information resources dimensions in the post-test in comparison to pre-test at $\mathrm{p} \leq 0.001$. The improvement of nursing students' ability in an effective use of information resources of evidence lead to promoting evidence-based practice. The current study finding was consistent with Dalheim et.al, who revealed that information resources were significant with the skills in evidence-based practice. ${ }^{(32)}$ Also, Majid, mentioned that accessing to current, and relevant research information of evidence is becoming essential for nurses to improve EBP. ${ }^{(31)}$

Concerning the barriers affect developing evidence-based practice among nursing students at Shaqra University. The current study findings reported that the majority of nursing students identified major barriers were; inability to understand statistics terms $(60.0 \%)$, inability to understand research items (59.0\%), difficulty in judging the quality of research articles ( $55.0 \%$ ) and inability to properly interpret the results of research studies $(54.0 \%)$. The next barriers, identified by more than third of students agreed that they don't have authority for change (40\%), lack of time for reading research (37.0\%), and inability to apply research results (33\%).

These findings were consistent with the study of Mohsen et al. which indicated that barriers for implementing of evidence-based practice among nurses were; difficulty in judging the quality of research articles and reports, lack of time at the workplace to read research articles. ${ }^{(33)}$ Also in the same respect, Mclnerney, revealed a lack of information searching skills as a barrier for applying evidence-based practice by students. ${ }^{(34)}$

Furthermore, the current study findings were in line with Majid et al. (2011), they reported that more than 53\% of the nurses identified the major barriers to adopting of EBP were; the lack of time to read research articles, difficulty in judging the quality of research articles and reports and inability to understand statistical terms. ${ }^{(12)}$ On the other hand, Breimaier et al., indicated that majority of nurses considered research utilization and nursing research as an advantageous aspect in nursing care. ${ }^{(35)}$

\section{Conclusion}

EBP education and training intervention was an effective mechanism for improving EBP knowledge, skills and attitude levels in the clinical nursing practice. The results of the current research showed that EBP knowledge, skills and attitude among nursing students were improved after an education and training intervention. While, there was highly statistically significant difference between the experimental group and comparison group in their EBP' knowledge and skills after an intervention, while, the two groups different significantly in their attitude toward EBP, indicating the efficacy of the education and training intervention in improving EBP' knowledge, skills, and attitudes among nursing students at Shaqra University. The study findings revealed highly statistically significant improvements in the three information resources dimensions (print, electronic and human) in the post-test in comparison to pre-test. The most common barriers to developing evidence- based practice among nursing students were; inability to understand statistics terms, inability to understand research items, difficulty in judging the quality of research articles and inability to properly interpret the results of research studies.

\section{Recommendation}

Based on the findings of this study, the following recommendations are suggested: Firstly, planning various strategies to smooth the progress of research utilization by nurses in their clinical practice. Secondly, providing time for undergraduates and graduate nurses students to learn and implement new techniques for application of EBP. Thirdly, more advanced training are warranted to expand learning on the judging the quality of research articles, interpreting the results of research studies and statistic items. Fourthly, facilitate access to digital libraries, Medline, CINAHL, computers, and the internet for online searching of evidence-based nursing practice. Fifthly, Giving attention to the nursing students about the importance of research utilization in clinical practice for empowering them to implement EBP; sixthly, providing ongoing training and education and systematic support for undergraduate and postgraduate nurse's students to develop EBP' skills. Finally, Create nursing Model for implementing evidence-based practice in the clinical practice.

\section{References}

[1]. Makic MBF, Martin SA, Burns' S, Philbrick D, Rauen C. Putting evidence into practice: four traditional practices not supported by the evidence. Critical Care Nurse.2013; 33(2):28-44.).

[2]. Schulman, C. S. (2008). Strategies for starting a successful evidence-based practice program. AACN Advanced Critical Care, 19(3), 301-311; quiz312-313.doi:10.1097/01.AACN.0000330381. 41766.2a

[3]. Soukup, M., \& McCleish, J. (2008). Advancing evidence-based practice: A program series. Journal of Continuing Education in Nursing, 39(9), 402-406.

[4]. Manspeaker SA., Van Lunen BL., Turocy PS., Pribesh S., Hankemeier D. (2011). Student knowledge, attitudes, and use of evidence-based concepts following an educational intervention. Athl Train Educ J. 6(2):88-98). 
Improvement of Evidence-Based Practice through Education and Training Interventions among ..

[5]. Godin, G., Beranger - Gravel, A., Eccles, M., \& Grimshaw, J.(2008). Health care professionals 'intentions and behaviors: A systematic review of studies based on social cognitive theories. Implementation Science, 16, 3-36. doi: 10.1186/1748-5908-3-36.

[6]. Lim, A., B.J. Nakamura, C.K. Higa-McMillan, S. Shimabukur and Slavin, L. (2012). Effects of workshop trainings on evidence-based practice, knowledge and attitudes among youth community mental health providers. Behaviour Research and Therapy, 50: 397-406.

[7]. Mosby's Medical Dictionary (2009). Mosby's Nursing Consult, 9th edition. St. Louis: MO Elsevier Mosby.

[8]. Houser, J., and Oman, K. (2011). EVIDENCE-BASED PRACTICE: An Implementation Guide for Healthcare Organizations. Canada. Jones \& Bartlett Learning\&. (2012 by International Council of Nurses. INTERNATIONAL NURSES DAY .CLOSING THE GAP: FROM EVIDENCE TO ACTION.

[9]. Oman, K. S., Duran, C., \& Fink, R. (2008). Evidence-based policy and procedures: An algorithm for success Journal of Nursing Administration 38(1) 4751

[10]. Hughes, R (2008): Patient Safety and Quality; an Evidence-Based Handbook for Nurses. Agency for Healthcare Research and Quality (US);http://www.ncbi.nlm.nih.gov/books/NBK2651.

[11]. Melnyk,B \& Fineout-Overholt,E (2011): Evidence-Based Practice in Nursing \& Healthcare: A Guide to Best Practice. 3rd edition. Wolters Kluwer.

[12]. Public Health Action Support Team (PHAST) 2011:Identifying and Evaluating Sources of Evidence, available at: http://www.healthknowledge.org.uk/interactive-learning/fae/finding-the-evidence/identifying-evaluating-sources-evidence.

[13]. Majid, Sh., Foo, S., Luyt, B., Theng, Y., and Chang, Y. (2011). Adopting evidence-based practice in clinical decision making: nurses' perceptions, knowledge, and barriers. J Med Libr Assoc. Jul; 99(3): 229-236.

[14]. Asadoorian J, Hearson B, Satyanarayana S, Ursel J. Evidence based practice in dental hygiene: exploring the enhancers and barriers across disciplines. Can J Dent Hyg. 2010;44(6):271-6.

[15]. Fathimath Shifaza, David Evans, and Helen Bradley Nurses' Perceptions of Barriers and Facilitators to Implement EBP in the Maldives, Hindawi Publishing Corporation, Advances in Nursing Volume 2014, Article ID 698604, 7 pages.

[16]. Griffiths J.M, Closs S.J, Bryar R.M, Hostick T, Kelly S, Cooke J. Barriers to research implementation by community nurses. Br J Community Nurs. 2001;6(10):501-10.

[17]. Cameron, K. S., and Quinn, R. E. (2006). Diagnosing and changing organizational culture: Based on the competing values framework. San Francisco: John Wiley \& Sons

[18]. Sun, W., Chou, C.P., Stacy, A.W., Unger, J., and Gallaher, P. (2007). SAS and SPSS macros to calculate standardized Cronbach's alpha using the upper bound of the phi coefficient for dichotomous items. Behavior Research Methods, 39 (1), 71-81.

[19]. Tavakol, M., \&and Dennick, R. (2011) Making sense of Cronbach's alpha. International Journal of Medical Education. 2:53-55. ISSN: 2042-6372.

[20]. Ramos-Morcillo, A., Fern’andez-Salazar, S., and Ruzafa-Mart'inez, M. (2015). Effectiveness of a Brief, Basic Evidence-Based Practice Course for Clinical Nurses, Worldviews on Evidence-Based Nursing; 12:4, 199-207.

[21]. Melnyk B., Fineout-Overholt E., Fischbeck Feinstein N., Li H., Small L., Wilcox L. \& Kraus R. (2004) Nurses' perceived knowledge, beliefs, skills, and needs regarding evidence-based practice: implications for accelerating the paradigm shift. Worldviews on Evidence-based Nursing 1(3), 185-193.

[22]. Olade, R.A. (2004) Evidence-based practice and research utilization activities among rural nurses. Journal of Nursing Scholarship, $36(3), 220-225$

[23]. Laibhen-Parkes N and Codone S. (2014). Web-based evidence based practice educational intervention to improve EBP competence among BSN-prepared pediatric bedside nurses: a mixed methods pilot study. J Nurs. 1:2.

[24]. Ashktorab, T., Pashaeypoor, Sh., Rassouli, M., and Majd, H. (2014). The Effectiveness of Evidence Based Practice Education in Nursing Students Based on Rogers's Diffusion of Innovation Model. Middle-East Journal of Scientific Research 19 (10): 13881395.

[25]. Varnell G, Haas B, Duke G and Hudson K. Effect of an educational intervention on attitudes toward and implementation of evidence based practice. Worldviews Evid Based Nurs. 2008; 5:172-81.

[26]. Welch, C., Van Lunen, B., and Hankemeier, D. (2014) An Evidence-Based Practice Educational Intervention for Athletic Trainers: A Randomized Controlled Trial.

[27]. Eldeeb, G., and Bakeer, H. (2016) Effect of an Educational Program on Nursing Interns` Evidence Based Practice Attitude, Knowledge and Skills. Journal of Nursing and Health Science (IOSR-JNHS) Volume 5, Issue 3 Ver. 1, PP 12-18 www.iosrjournals.org.

[28]. Mollon, D., Fields, W., Gallo, A. M., Wagener, R., Soucy, J., Gustafson, B., \& Kim, S. C. (2012). Staff practice, attitudes, and knowledge/skills regarding evidence-based practice before and after an educational intervention. Journal of Continuing Education in Nursing, 43(9), 411-419. doi: 10.3928/00220124-2012071689.

[29]. Kim, S. C., Brown, C. E., Ecoff, L., Davidson, J. E., Gallo, A. M., Klimpel, K., \& Wickline, M. A. (2013). Regional evidence-based practice fellowship program: Impact on evidence-based practice implementation and barriers. Clinical Nursing Research, 22(1), 5169. doi: 10.1177/1054773812446063.

[30]. Gonz'alez-Torrente, S., Pericas-Beltr’an, J., Bennasar-Veny, M., Adrover-Barcel'o,R.,Morales-Asencio,J.M.,\&DePedro-G’omez, J. (2012). Perception of evidence-based practice and the professional environment of primary health care nurses in the Spanish context: A cross-sectional study. BMC Health Services Research, 12, 227-236. doi: 10.1186/1472-6963-12-227.

[31]. Majid, Sh., Foo, S., Luyt, B., Theng, Y., and Chang, Y. (2011). Adopting Evidence-based practice in clinical decision making: nurses' perceptions, knowledge, and barriers. J Med Libr Assoc. Jul; 99(3): 229-236.

[32]. Dalheim, A., Harthug, S., M Nilsen, R., and Nortved, M. (2012). Factors influencing the development of evidence-based practice among nurses: a self-report survey. BMC Health Services Research 12(1):367.

[33]. Mohsen, M., Nahla Ashour, N., and Okby, O.(2016): Nurses' Perceptions and Barriers for Adoption of Evidence Based Practice in Primary Care: Bridging the Gap. American Journal of Nursing Research, 4(2), 25-33.

[34]. Mclnerney P., and Suleman F. (2010); Exploring knowledge, attitudes, and barriers toward the use of evidence-based practice amongst academic health care practitioners in their teaching in a South African university: a pilot study. Worldviews Evid Based Nurs. 7(2):90-7.

[35]. Breimaier, H. E., Halfens, R. JG and Lohrmann, C. (2011): Nurses' wishes, knowledge, attitudes and perceived barriers on implementing research findings into practice among graduate nurses in Austria. Journal of Clinical Nursing, 20, 1744-1756. 